Int. J. Curr. Res. Med. Sci. (2017). 3(5): 110-114

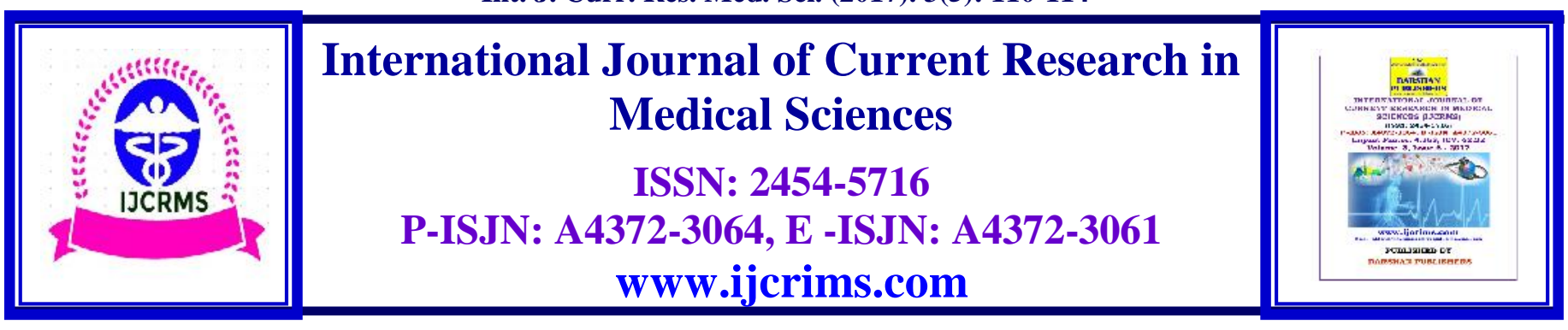

Original Research Article

Volume 3, Issue 6 -2017

DOI: http://dx.doi.org/10.22192/ijcrms.2017.03.06.015

\title{
Submandibular Stones in Sudanese Patients
}

\author{
${ }^{1}$ Dr. Yousif Mohammed Yousif, MBBS, M D, \\ Faculty of Medicine , Khartoum University - Sudan, Associate Professor of Otorhinolaryngology \\ Faculty of Medicine Shendi University Sudan. \\ ${ }^{2}$ Dr. Esam Edin Bakhit, MBBS, Gezira, MD, SMSB, \\ Sudan, Assistant Professor of Otorhinolaryngology Faculty of Medicine Shendi University Sudan.
}

\author{
Correspondence: Dr. Yousif Mohammed Yousif \\ Shendi University Faculty of Medicine \\ Mobile 00249912279873 \\ E-mail:yousifent@yahoo.com
}

\begin{abstract}
This is retrospective study of 10 years experience of management of Sudanese patients with Submandibular ductal and glandular stones seen in Elmak Nimer university hospital and private clinic in Shendi north of Sudan between 2006-2016.

Objectives

The aim of the study to study the common presenting symptoms and signs ,management and the possible risk factors which increase the incidence of the Submandibular gland stones in the area of the study.

Design

This retrospective study showed the experience of the authors in the management of Submandibular stones between $2006-2016$.

Conclusion

Submandibular stones are one of the common causes of sore throat and pain with chewing in Sudanese patients.

Males are affected more than females.

Hot weather and snuff use may play role in increased formation stones in the area of study.
\end{abstract}

Keywords: Submandibular gland, sore throat, swelling. Stone formation. Mursuplisation, submandibulectomy.

\section{Introduction}

Salivary gland diseases was first described in ancient times by Hippocrates, 460-370 Bc. There are three pairs of salivary glands and many minor ones .the classical investigations include plain radiography, ultrasonography, CT scan and sialography. Most radiologist consider computed tomography to be more reliable for demonstration of Submandibular ductal or glandular stones ${ }^{[2,3,5]}$ Sialoadenitis of Submandibular gland is diagnosed depending on the history of recurrent pain full swelling in the Submandibular gland area which exacerbated by chewing ${ }^{[1,3,6,7,8)}$. 
Calculus obstructions commonly result in persistent swelling of the gland with intermittent pain full episodes .According to post autopsy studies; sialolithaisis affect $1 \%$ of the salivary glands ${ }^{[4,9 \text { WilsonKF] }}$.

According to most published data Submandibular gland stones account 80-90\% of all cases while parotid account $6-10 \%$ and rare in minor salivary glands ${ }^{[5]}$.

Many factors may play role in the formations of stones this includes decrease salivary flow. Dehydration, infection, auto immune diseases and chronic irritation.

The salivary gland stones composed of organic and inorganic substances in varying ratio. The organic substances include glycoproteins, muco poly saccharides and cellular debris the inorganic substances are mainly calcium carbonate and calcium phosphate ${ }^{[6]}$.

Submandibular stones can be located distally, proximally or intraglandular and it is of varying size, and can be single or multiple ${ }^{[7]}$.

Diagnoses depend on typical history of recurrent pain full swelling or persistent neck swelling in the submandibular area.

Ductal stone in submandibular gland are often visible or can be bi manually palpable while intraglandular are difficult to feel but can be visible in plain $\mathrm{X}$ rays or C.T scan and occlusal film may play arole ${ }^{[8]}$.

Ductal stones can be removed through the mouth by local anesthesia with adrenaline. Patient with big stones, recurrent sialoadenitis and persistent swelling submandibulectomythrough external incision should be done ${ }^{[9]}$. Sialoendoscopy is a new procedure, aiming to visualize the lumen of salivary duct, their pathology and may play a good role in the management of ductal stones ${ }^{[10]}$.

\section{Patients and Methods}

These study included all cases of submandibular gland and ductal stones seen in ENT referred of ELMAC NIMER university hospital and private clinic of one of the authors in the period between 2006-2016 .All cases were confirmed clinically and radio logically to had either glandular or ductal stones.

\section{Results}

The total number of patients involved in this study was 87 patients they confirmed clinically and radio logically to had either ductal, glandular or both submandibular stones.

Two third of them were males table1, their age range from 10-65 years old most of them in the third and fourth decades table [2]. Recurrent sore throats, pain on chewing and persistent submandibular swelling were the main presenting symptoms table[3].

Table [1] Sex distributions of patients in the study group.

\begin{tabular}{lcc}
\hline \multicolumn{1}{c}{ Sex of Pts } & No.of PTS & \% \\
\hline Male & & $71.2 \%$ \\
Female & 62 & $29.8 \%$ \\
Total & 25 & $100 \%$ \\
\hline
\end{tabular}

Table [2] Presenting symptoms of pts. With submandibular ductal and gland stones.

\begin{tabular}{lcc}
\hline \multicolumn{1}{c}{ Symptoms } & No.of PTS & \% \\
\hline Recurrent sore thorat & 80 & $91.2 \%$ \\
Pain with chewing & 32 & $36.80 \%$ \\
Submandibular swelling & 25 & $28.70 \%$ \\
Abscess formation & 8 & $9.20 \%$ \\
others & 36 & $41.40 \%$ \\
Total & & $100 \%$ \\
\hline
\end{tabular}


Others include irritation in the floor of the mouth, fever, halitosis \& pooling of saliva.

Table [3] Age distribution of pts. In the study.

\begin{tabular}{l|cc}
\hline Age group & No. of PTS & $\%$ \\
\hline Less than 10Ys & 0.00 & $0 \%$ \\
\hline $\mathbf{1 0 - 2 0}$ & 5.0 & $5.70 \%$ \\
\hline $\mathbf{2 0 - 3 0}$ & 32.0 & $36.80 \%$ \\
$\mathbf{3 0 - 4 0}$ & 27.0 & $31.00 \%$ \\
$\mathbf{4 0 - 5 0}$ & 12.0 & $13.80 \%$ \\
More than 50 ys & 13.0 & $14.90 \%$ \\
\hline Total & 87.0 & $100 \%$ \\
\hline
\end{tabular}

Some patients showed silent symptoms and discovered during routine examinations of the throat. Clinical examination play the major role in diagnosis and bimanual examination was significant in most cases.
Radiological assessment in most cases confirmed radiopaque stones which can be single and multiple in some cases in the study. Fig [1\&2]

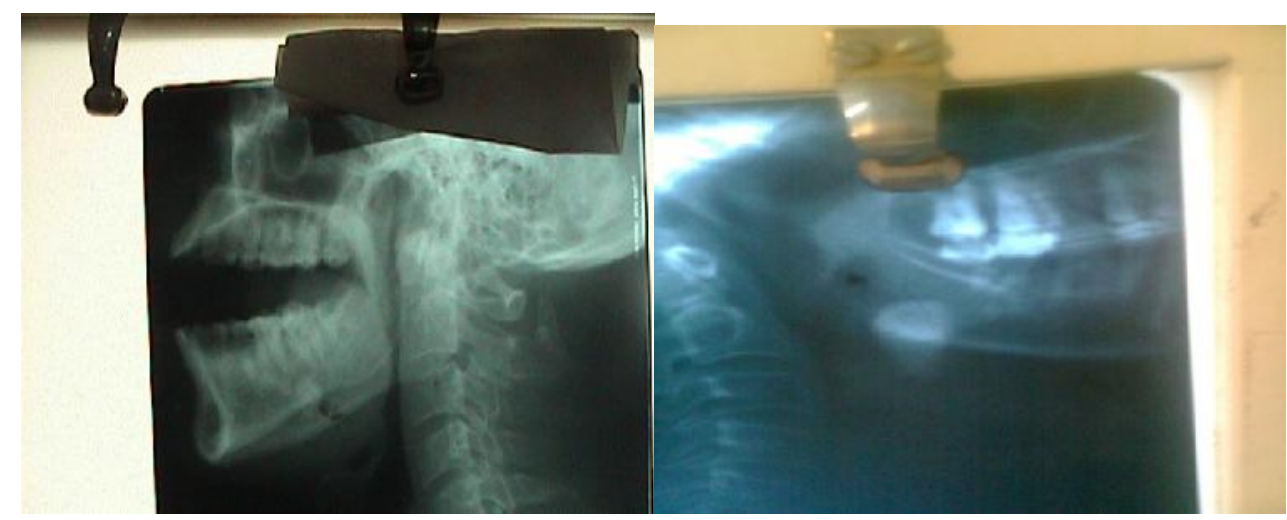

Fig (1) X rays showed multiple stones Fig (2) X rays showed glandular stone

Some patients in the study is not believe about presence of stones in this area.
All patients who had ductal stones removed in outpatients or in private clinic with mursuplisation of Wharton duct under local anesthesia

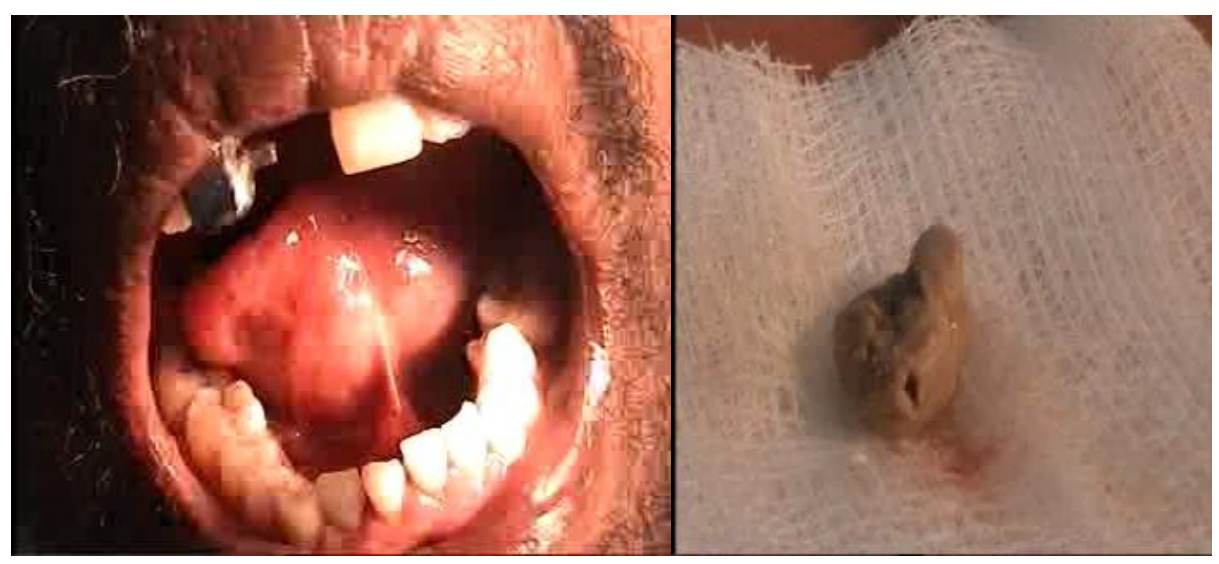

Figure (3): Ductal stone removed under local anesthesia. 
Fourteen patients with big stones .recurrent stones formation or persistent swelling sub- mandibulectomy under general anesthesia was conduct:

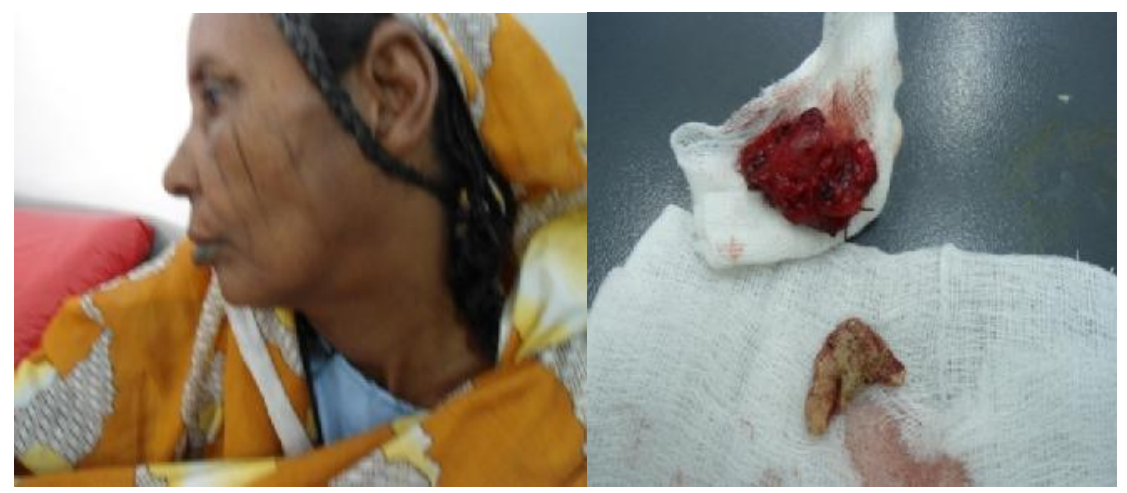

Figure (4 \& 5): patient with glandular stone which showed huge stone after surgery

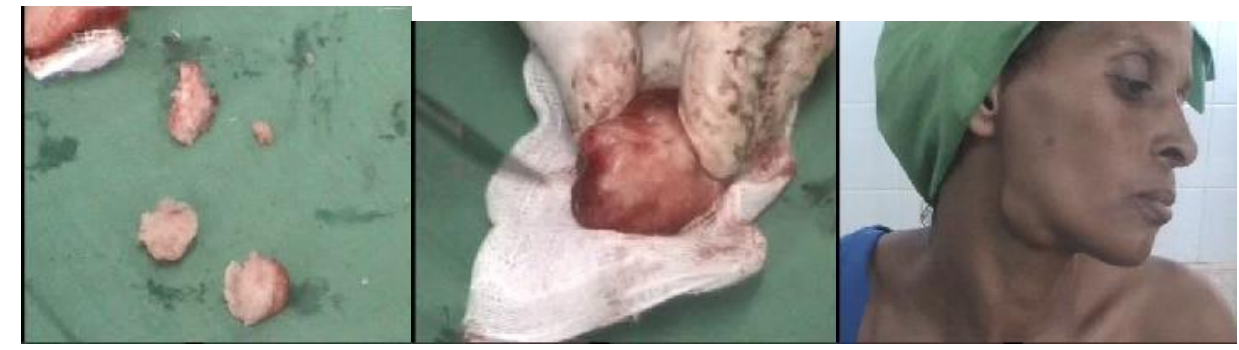

Figure (5): patients with glandular stones and showed multiple stones after surgery

Most of the patients with silent symptoms or discovered on routine throat examinations refused surgery.

No patient in the study showed bilateral stone formations .Recurrent stone formation was noticed in five cases after removal of ductal stones.

The study of possible risk factors revealed that $80 \%$ of the male patients were snuff user which increased incidence of bad oral hygiene also we noticed the increased exacerbation of the symptoms in the summer in which the temperature reach up $45 \mathrm{c}$ in the area of the study.

\section{Discussion}

This is retrospective study done in Shendi northof Sudan .To study the experience of the authors to manage patients with submandibular ductal and glandular stones between 2006-2016.
No previous study in Sudanese patients especially in the study area.

The major presenting were recurrent sore throat ,pain chewing with or without persistent swelling and this goes with most published literature where recurrent sialoadenitisas the main presenting feature of submandibular gland and ductal stone. ${ }^{[1]}$

In reviewing of our data we noticed that submandibular salivary diseases are common specially sialoadenititis and sialolithiasiswhich increased by bad oral hygiene and hotweather in the study area in which environmental temperature reach up to $45 \mathrm{c}$ in summer.

Two third of the patients are males in the $3^{\text {rd }}$ and $4^{\text {th }}$ decades and most of them are snuff users and it increase therisk of sialoadenitis which increased stone formation. 
Int. J. Curr. Res. Med. Sci. (2017). 3(5): 110-114

\section{Conclusion}

Submandibular stones are one of the common causes of sore throat and pain with chewing in Sudanese patients.

Males are affected more than females.

Hot weather and snuff use may play role in increased formation stones in the area of study.

\section{References}

1.Hugh D.Curtin .imaging of salivary glands , Salivary Gland Diorders.chapter2 ,Eugene N.Myers, Robert,Ferris, Springer -verlag Berlin Heidelberg 2007.

2.MRCHAL.Francis, M,D. Geneva, Switzerland the endoscopic approach to salivary glands ductal pathologies in Sialoendoscopy, Tulting ,Germany :endo press2004 p(6,7,19,12).

3. Maran.A.G.D Non-neoplastic salivary gland diseases. In: kerr G.Allan, hibbertjohn, Editors. Scott-Brown's otolaryngology, $6^{\text {th }}$ edition. Ondon: Butterworth-Heinemann, 1997 volume 5.p5\19\4\6.
4. JOSCPH. Achrstopttek. surgery of the submandibular and minor salivary glands in ;Bleach Nigel ;Milford Chris ,Hassel T Anderwvan, Editors. Operative Otorhinolaryngology Black well science, 1996p $(415,418)$.

5. FrelingN (2000) imaging of salivary gland diseases .SeminRoentgenol 35:12-20.

6.BatesD,Obrien CJ, Tikaram K,and Painter DM (1998) parotid andsubmandibularsialadenitis treated bysalivary gland excision .aust NJsurg68 (2):120-124.

7.wilson KF,MeierJD,wardPD,salivary gland disorders.American family physician .2014jun1;89(11).

8.ChandakR,DegwekarS,Chandak M,Rawlani S, acute submandibular sialadenitis-case reports in dentistry.2012jul24;2012.

9.YoskovitchA,submandibular Isialadenosis;e mediciene. June25(2515) Canada.

10. Robert (Byung) H.kim,MD.Nonoperative removal of sialoliths and sialoendoscopy of salivary duct stricture, Arch otolaryngology headneck surgery1996, 122:974-97

\begin{tabular}{|c|l|}
\hline \multicolumn{2}{|c|}{ Access this Article in Online } \\
\hline & Website: \\
\hline & www.ijcrims.com \\
\hline Quick Response Code & Subject: \\
\hline
\end{tabular}

How to cite this article:

Yousif Mohammed Yousif, Esam Edin Bakhit, Gezira. (2017). Submandibular Stones in Sudanese Patients. Int. J. Curr. Res. Med. Sci. 3(6): 110-114.

DOI: http://dx.doi.org/10.22192/ijcrms.2017.03.06.015 